\title{
Effect of pore structure and moisture content on gas diffusion and permeability in porous building stones
}

\author{
D. Benavente ${ }^{1, *}$, C. $\mathrm{Pla}^{2}$ \\ ${ }^{I}$ Departamento de Ciencias de la Tierra y del Medio Ambiente. Universidad de Alicante, \\ Alicante,Spain.david.benavente@ua.es \\ ${ }^{2}$ Departamento de Ingeniería Civil. Universidad de Alicante, Alicante, Spain. c.pla@ua.es \\ *Corresponding Author: david.benavente@ua.es
}

Departamento de Ciencias de la Tierra y el Medio Ambiente, Universidad de Alicante, Ap. 99, 03080 Alicante, Spain. Tel./fax: +0034-965-903727.

ORCID of the authors:

D. Benavente: 0000-0001-7325-4042

C. Pla: 0000-0002-4269-2426

\begin{abstract}
Hazardous gases in buildings are a concern for public health and security. These gases can be released from the building materials to indoor air and their concentration may become critical where ventilation is hindered, as such in hypogean or more energetically efficient airtight constructions. Furthermore, the gas ventilation and the indoor gas concentration can considerably increase by the vapour condensation on the ceiling and walls of buildings. In this paper, we characterise the $\mathrm{CO}_{2}$ gas diffusion for a representative range of building porous stones with the aim of establishing the effect of the water content in the gaseous diffusion coefficient.

We propose a new methodology to measure gas diffusion with a laboratory device that works under different hygrometric conditions. Results reveal water pore condensation reduces both connected porosity and pore size and therefore, the $\mathrm{CO}_{2}$ diffusion coefficient. This variation occurs in all the studied porous building stones although it is especially important in stones with small pores. Thus, the reduction of $\mathrm{CO}_{2}$ diffusion coefficient for the stone with thinnest pores is by $50 \%$ when relative humidity varies from 20 to $90 \%$.

Permeability and gas diffusion coefficients present similar trends. Porous stones with larger pores and higher porosity values present the highest $\mathrm{CO}_{2}$ diffusion, water and gas permeability coefficients. Pore size is the conclusive parameter within the transport coefficients. It greatly affects both the tortuosity factor of the $\mathrm{CO}_{2}$ gaseous diffusion and the slip parameter of the Klinkenberg's model for gas permeability coefficient. Finally, for studied samples, we establish a power regression, which correlates thoroughly both coefficients.
\end{abstract}

Keywords: $\mathrm{CO}_{2}$; built heritage; air quality; porous materials; indoor gas concentration. 


\section{Introduction}

Diffusion of hazardous gas such as ${ }^{222} \mathrm{Rn}, \mathrm{CO}_{2}, \mathrm{CO}, \mathrm{NH}_{3}$ and volatile organic compounds (VOCs) in an indoor environment has become a concern for public health and security, mainly as new building regulations are imposing airtight construction to reduce energy consumption [1]. Generally, $\mathrm{CO}_{2}$ is not considered harmful at levels routinely encountered in buildings [2]. However, the study of radon gas $\left({ }^{222} \mathrm{Rn}\right)$ nowadays concerns to many researchers $[3,4]$ since the exposition to radon in homes and workplace represents a potential hazard to human health [5, 6]. The soil and building materials are the main sources of indoor radon $[4,7,8]$, a natural radioactive gas that accumulates within buildings and consequently, is inhaled by their occupants $[9,10]$.

Indoor gas concentration can be significant in both modern buildings and monuments. More critical can become gas concentration in garages and cellars or hypogean constructions, with hindered ventilation. The vapour condensation on the ceiling and walls of these constructions reduces the gas ventilation and, therefore, the indoor gas concentration increases considerably [11]. Condensate water depends on the indoor climate conditions, pore structure and pore water of the material. It obstructs the direct passage of gases and modifies the gas diffusion coefficients. Previous studies in building stones [12] and cementitious materials [13-15] demonstrated that the gas diffusion coefficient decreases with the increase of relative humidity. In soils, this reduction in the gas diffusion coefficient has also been demonstrated when relative humidity increases. Besides, other authors [16-19] also reported the limitation of gas diffusion through soils with pore spaces filled with water.

In monuments, the indoor environment tends to be more stable than the outdoor climate and to fluctuate less and more slowly. Building materials include indoor elements (such as stone ashlars, clay-based materials, stuccos) and the unique works of art they enclose (i.e.: sculptures, paintings, frescoes) [20]. However, variations in the thermo-hygrometric conditions and the presence of small pores can raise the amount of moisture within the building element. In this situation, materials are partially saturated in water turning into an excellent context to its deterioration: water triggers salt and ice crystallisation, clay swelling, chemical deterioration and the development of microorganisms; reduces mechanical strength; and contributes to chemical weathering by the presence of $\mathrm{CO}_{2}$ [21-23].

Substantial research has been undertaken to measure gas diffusion coefficients in the soil [24, 25], less in cementitious materials [26] and few in building stones [1]. Most of the previous works have calculated the gaseous diffusion coefficients with both laboratories and in situ field measurements that, sometimes, are time-consuming, tedious, expensive and difficult to conduct [2]. Moreover, these measurements do not contemplate the moisture content in the material during the experiment, and therefore, do not consider the variation of gas diffusion coefficient by water condensation.

A different method to estimate gas diffusion in porous materials is via empirical relationships with the permeability coefficient [27]. Permeability describes the process of gas transport through porous materials due to pressure gradient. The permeability measure is relatively 
easily performed following standardised procedures [2, 10, 28-30]. Thus, gas diffusion is commonly assessed from permeability by empirical relationships that, in most cases, do not consider the type of porous material and gas.

The aim of this paper is to characterise the $\mathrm{CO}_{2}$ gas diffusion in different porous building stones. For this purpose, firstly, we propose a new methodology that includes the measuring of $\mathrm{CO}_{2}$ gaseous diffusion under different hygrometric conditions. Secondly, we quantify the variation of $\mathrm{CO}_{2}$ diffusion coefficients by water condensation in the building stones. Thirdly, we evaluate the influence of pore structure on permeability and diffusion coefficients, highlighting the role of pore connectivity and tortuosity. Finally, we empirically establish correlations between gas transport coefficients. Some practical aspects of this research focus on using gas and water permeability tests to estimate the gas diffusion coefficient.

\section{Experimental procedure}

\subsection{Materials}

In this study, we use five sedimentary rocks, which are employed as building materials or they are found in the Spanish built heritage. They present different petrophysical and petrographic characteristics. These building stones can be classified as biocalcarenites (C), sandstones (S), limestones (L) and dolostones (D).

$\mathrm{C} 1$ and $\mathrm{C} 2$ are well-sorted biocalcarenites and contain a variable amount of terrigenous components (quartz, feldspar, mica and dolomite grains) and fossils (mainly foraminifera), and they present intergranular porosity [31-33]. S3, with intergranular porosity [31], is a well-sorted sandstone mainly composed of monocrystalline quartz grains. D4 shows mesocrystalline calcite cement and intergranular porosity [31-33]. The dolostone is a well-sorted sandstone consisting of dolomite (75\%) and calcite (25\%) grains. L5 is a limestone with intergranular porosity [31] and a wide range in the size and type of allochems (mainly bivalves, bryozoans and red algae).

\subsection{Methods}

\subsubsection{Sample preparation}

From each sedimentary rock, $3 \mathrm{~cm}$ diameter and $6 \mathrm{~cm}$ length samples were cored. Every cored sample was tested in order to obtain water and gas permeability and some porous media measurements (bulk and grain densities) (Table 1). Different samples $(5 \mathrm{~cm}$ diameter and $1 \mathrm{~cm}$ thick) were employed to measure $\mathrm{CO}_{2}$ gas diffusion and water adsorption. Finally, mercury injection test requested core-plug samples of $1.5 \mathrm{~cm}$ diameter and $1.5 \mathrm{~cm}$ long, whereas circa $10 \mathrm{~g}$ pieces of samples (3-5 mm wide) were used in the nitrogen and water adsorption characterisations.

\subsubsection{Porous space characterization}

Pore structure was described in terms of porosity, pore size distribution and specific surface area, using mercury intrusion porosimetry (MIP), the nitrogen and water adsorption techniques, and the helium pycnometer (Table 1). 
Table 1. Bulk, $\rho b$, and grain, $\rho d$, densities; connected, $\phi_{\mathrm{c}}$, and total, $\phi_{\mathrm{T}}$, porosities; pore mean radius, $\mathrm{r}_{\mathrm{M}}$; specific surface area, $\mathrm{SSA}$; pore volume, $\mathrm{v}_{\mathrm{P}}$; maximum adsorbed water, $\Delta \mathrm{m} / \mathrm{m}_{0, \max }$; percentage of the occupied porosity by capillary condensation, $\mathrm{P}_{\text {con }}$; water, $\mathrm{k}_{\mathrm{w}}$, and intrinsic, $\mathrm{k}_{\text {int }}$, permeability; and the slip parameter, $b$, for the studied stones.

\begin{tabular}{|c|c|c|c|c|c|}
\hline Sample & $\begin{array}{c}\text { Biocalcarenite } \\
\text { C1 }\end{array}$ & $\begin{array}{c}\text { Biocalcarenite } \\
\text { C2 }\end{array}$ & $\begin{array}{c}\text { Sandstone } \\
\text { S3 }\end{array}$ & $\begin{array}{c}\text { Dolostone } \\
\text { D4 }\end{array}$ & $\begin{array}{c}\text { Limestone } \\
\text { L5 }\end{array}$ \\
\hline$\rho_{\mathrm{b}}\left[\mathrm{g} \mathrm{cm}^{-3}\right]$ & $2.26 \pm 0.11$ & $2.11 \pm 0.11$ & $2.28 \pm 0.15$ & $2.22 \pm 0.05$ & $2.16 \pm 0.12$ \\
\hline$\rho_{\mathrm{g}}\left[\mathrm{g} \mathrm{cm}^{-3}\right]$ & $2.70 \pm 0.09$ & $2.71 \pm 0.15$ & $2.67 \pm 0.08$ & $2.79 \pm 0.13$ & $2.71 \pm 0.16$ \\
\hline$\phi_{\mathrm{c}}[\%]$ & $14.31 \pm 0.06$ & $18.83 \pm 0.08$ & $13.48 \pm 0.06$ & $19.52 \pm 0.09$ & $16.32 \pm 0.09$ \\
\hline$\phi_{\mathrm{T}}[\%]$ & $16.30 \pm 0.09$ & $22.14 \pm 0.09$ & $14.61 \pm 0.05$ & $20.43 \pm 0.09$ & $20.30 \pm 0.06$ \\
\hline $\mathrm{r}_{\mathrm{M}}[\mu \mathrm{m}]$ & $0.08 \pm 0.02 \cdot 10^{-1}$ & $1.48 \pm 0.05$ & $2.43 \pm 0.07$ & $6.71 \pm 0.09$ & $34.18 \pm 0.25$ \\
\hline $\mathrm{SSA}\left[\mathrm{m}_{2} \mathrm{~g}^{-1}\right]$ & $10.22 \pm 0.25$ & $8.42 \pm 0.11$ & $2.31 \pm 0.05$ & $0.69 \pm 0.02$ & $0.83 \pm 0.06$ \\
\hline $\mathrm{V}_{\mathrm{P}}\left[\mathrm{cm}^{3} \mathrm{~g}^{-1}\right]$ & $1.80 \cdot 10^{-2} \pm 0.07 \cdot 10^{-2}$ & $1.26 \cdot 10^{-2} \pm 0.05 \cdot 10^{-2}$ & $5.11 \cdot 10^{-3} \pm 0.09 \cdot 10^{-3}$ & $1.49 \cdot 10^{-3} \pm 0.05 \cdot 10^{-3}$ & $5.00 \cdot 10^{-4} \pm 0.09 \cdot 10^{-4}$ \\
\hline$\Delta \mathrm{m} / \mathrm{m}_{0, \max }[-]$ & $1.90 \cdot 10^{-2} \pm 0.08 \cdot 10^{-2}$ & $1.21 \cdot 10^{-2} \pm 0.08 \cdot 10^{-2}$ & $5.35 \cdot 10^{-3} \pm 0.10 \cdot 10^{-3}$ & $3.52 \cdot 10^{-3} \pm 0.12 \cdot 10^{-3}$ & $1.80 \cdot 10^{-3} \pm 0.06 \cdot 10^{-3}$ \\
\hline $\mathrm{P}_{\text {con }}[\%]$ & $29.95 \pm 0.05$ & $13.55 \pm 0.03$ & $9.05 \pm 0.01$ & $4.01 \pm 0.01$ & $2.38 \pm 0.04$ \\
\hline $\mathrm{k}_{\mathrm{w}}\left[\mathrm{m}^{2}\right]$ & $4.00 \cdot 10^{-18} \pm 0.06 \cdot 10^{-18}$ & $1.40 \cdot 10^{-14} \pm 0.08 \cdot 10^{-14}$ & $2.02 \cdot 10^{-15} \pm 0.06 \cdot 10^{-15}$ & $2.28 \cdot 10^{-13} \pm 0.06 \cdot 10^{-13}$ & $1.25 \cdot 10^{-12} \pm 0.01 \cdot 10^{-12}$ \\
\hline $\mathrm{k}_{\mathrm{int}}\left[\mathrm{m}^{2}\right]$ & $3.00 \cdot 10^{-17} \pm 0.07 \cdot 10^{-17}$ & $7.14 \cdot 10^{-15} \pm 0.06 \cdot 10^{-15}$ & $1.83 \cdot 10^{-15} \pm 0.03 \cdot 10^{-15}$ & $2.62 \cdot 10^{-13} \pm 0.04 \cdot 10^{-13}$ & $7.07 \cdot 10^{-13} \pm 0.03 \cdot 10^{-13}$ \\
\hline $\mathrm{b}$ [atm] & $0.82 \pm 0.01$ & $0.76 \pm 0.01$ & $0.70 \pm 0.02$ & $0.53 \pm 0.03$ & $0.20 \pm 0.01$ \\
\hline
\end{tabular}

Total porosity, $\phi_{\mathrm{T}}$, is the fraction of the volume of voids over the bulk material volume and may be calculated from bulk and grain densities. Bulk density was determined as the ratio of dry weight to the volume of the sample. Grain density was obtained using an AccuPyc 1330 Helium pycnometer [34].

The connected porosity, $\phi_{\mathrm{c}}$, only considers connected voids. The connected porosity and mean throat-pore radius, $r_{M}$ (Table 1), were obtained from mercury intrusion porosimetry (MIP) with an Autopore IV 9500 Micrometrics mercury porosimeter in the pore size interval of 0.002$200 \mu \mathrm{m}$. Figure 1 shows the throat-pore size distribution of each stone. Specific surface area, SSA, and pore volume, $\mathrm{v}_{\mathrm{P}}$, was determined with the nitrogen adsorption technique, using an Autosorb-6 Quantachrome apparatus. The sorption isotherm is type IV and the pore volume is calculated as the liquid volume at $\mathrm{P} / \mathrm{P}_{0}=0.95$. According to the Kelvin equation, the related pore radius at $\mathrm{P} / \mathrm{P}_{0}$ $=0$ is $0.01 \mu \mathrm{m}$. The determination of the SSA was carried out by the BET method in the relative pressure interval $\mathrm{P} / \mathrm{P}_{0}=0.05-0.2$.

The adsorption curve (static method) was determined at long exposure time and constant temperature (isothermal equilibrium conditions) (Fig. 2). Humidity was controlled by selected aqueous saturated salt solutions: $\mathrm{H}_{2} \mathrm{O}$ (100\%); $\mathrm{KCl}(85 \%) ; \mathrm{NaCl}(75 \%) ; \mathrm{Mg}\left(\mathrm{NO}_{3}\right)_{2} \cdot 6 \mathrm{H}_{2} \mathrm{O}(53 \%)$; $\mathrm{K}_{2} \mathrm{CO}_{3} \cdot 2 \mathrm{H}_{2} \mathrm{O}(43 \%)$; and $\mathrm{CaCl}_{2} \cdot 6 \mathrm{H}_{2} \mathrm{O}(29 \%)$. The elapsed time to reach equilibrium depended on relative humidity: approximately a week for low relative humidity and 6-8 weeks for high relative humidity. The adsorption curve was plotted as the mass of water adsorbed per unit of dried sample, $\Delta \mathrm{m} / \mathrm{m}_{0}$, versus relative humidity, RH. The maximum adsorbed water, $\Delta \mathrm{m} / \mathrm{m}_{0}$, max , was calculated as the mass of water adsorbed per unit of dried sample at $\mathrm{RH}=100 \%$. The maximum adsorbed water can be also referred to gravimetric water content, $\theta_{\mathrm{g}}$. 


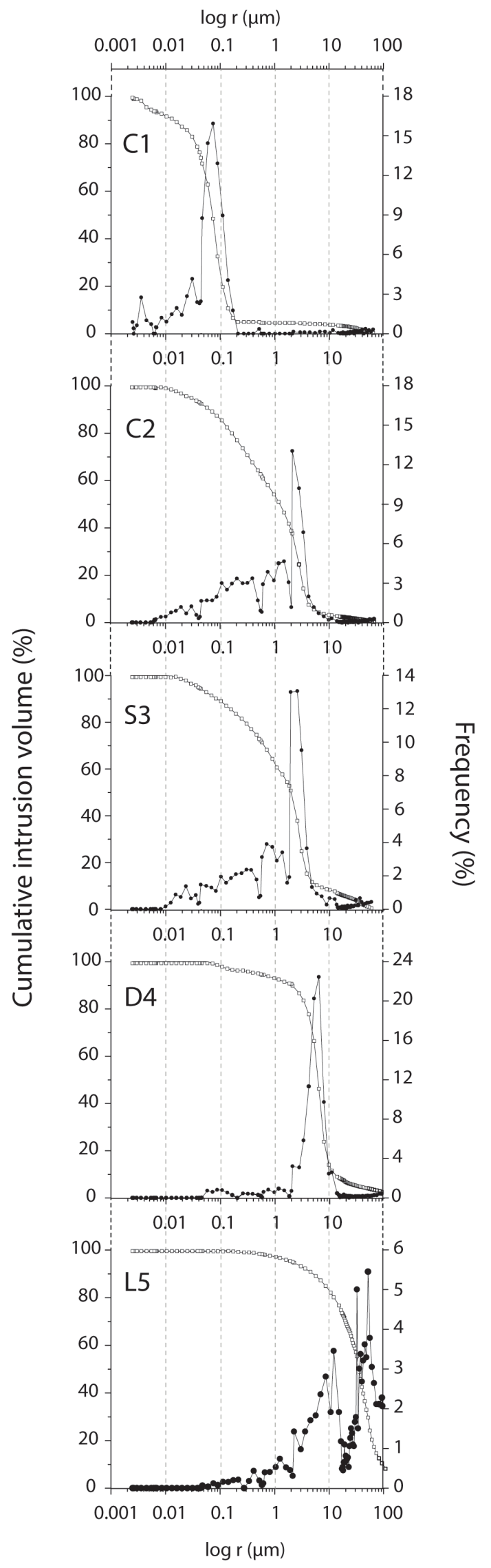

Fig. 1. Pore size distribution curves of the samples. 


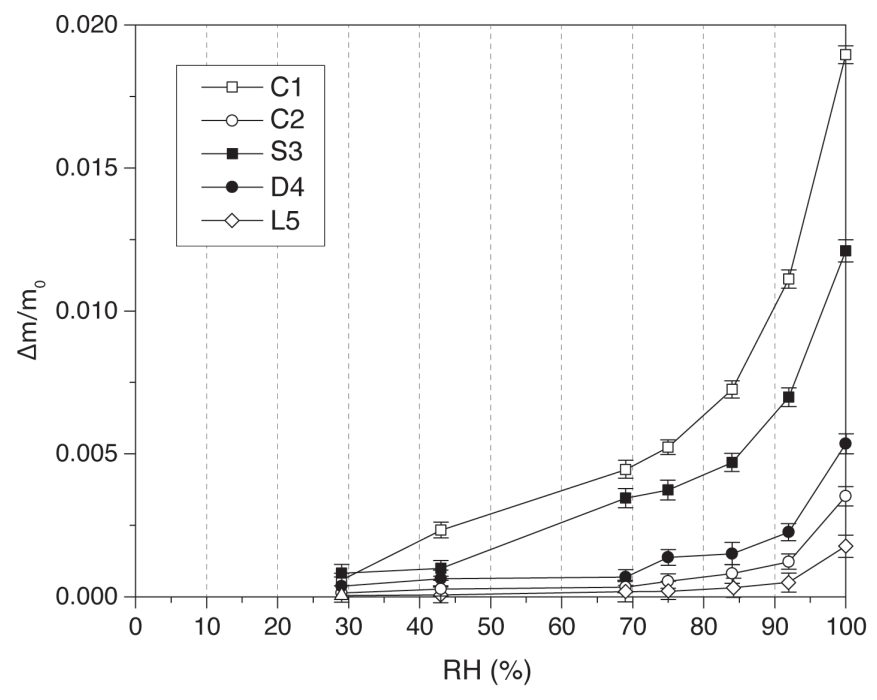

Fig. 2. Water adsorption $\left(\Delta \mathrm{m} / \mathrm{m}_{0}\right)$ curves over a range of relative humidity.

Water permeability, $\mathrm{k}_{\mathrm{w}}$, was measured on water-saturated samples, after vacuum water saturation test. Water permeability tests were performed in a triaxial device with an automatic pressure system using the steady-state method [35, 36]. The confining, inflow and outflow pressures in the triaxial method were 13, 7 and 3 bars, respectively. Water permeability was calculated according to Darcy's equation in steady-state conditions (water flow rate at inflow equals to water outflow rate).

In contrast to liquids, gas permeability depends on head pressure because mean free path effects and pressure-dependent wall slippage. Under steady state and laminar flow conditions, Klinkenberg [37] demonstrated that the permeability of porous media to gases, $\mathrm{k}_{\mathrm{g}}$, is approximately a linear function of the reciprocal mean pressure, $\mathrm{P}$, as follows (Eq. 1):

$$
\mathrm{k}_{\mathrm{g}}=\mathrm{k}_{\mathrm{int}}(1+\mathrm{b} / \mathrm{P})
$$

$\mathrm{k}_{\mathrm{int}}$ is the gas intrinsic permeability or corrected Klinkenberg's permeability, which is independent of the mean pressure, $\mathrm{k}_{\mathrm{g}}$ is the apparent permeability for given pressure, and $\mathrm{b}$ is the slip parameter that depends on the percolating gas and porous medium. Gas permeability was performed on dried samples using nitrogen at different inlet and outlet pressures (from 1 to 3 atm). The apparent permeability coefficient was calculated following Darcy's equation in steady-state conditions at each pressure, from which the gas intrinsic permeability was determined by way of Klinkenberg's correction (Eq. 1). The coefficients of regression of the least-squares fit in the Klinkenberg's method were always greater than 0.99 .

\subsection{3. $\mathrm{CO}_{2}$ gas diffusion coefficient}

$\mathrm{CO}_{2}$ gas diffusion coefficient was measured in a laboratory device [18], which consists of two vertical differentiated chambers $(5 \mathrm{~cm}$ diameter and $20 \mathrm{~cm}$ height) with the same volume 
separated by a sealed cell where the sample is placed (Fig. 3). An injection of $\mathrm{CO}_{2}$ gas (4000 ppm) maintained a constant concentration in the bottom cell. In the top chamber, the $\mathrm{CO}_{2}$ concentration was maintained at $0 \mathrm{ppm}$ at the beginning of the experiment. The concentration gradient between the two chambers ensures the diffusion process. $\mathrm{CO}_{2}$ flux, $\mathrm{F}\left(\mathrm{mol} \mathrm{m} \mathrm{m}^{-2} \mathrm{~s}^{-1}\right)$ is described by the Fick's first law of gas diffusion (Eq. 2), modified to calculate the $\mathrm{CO}_{2}$ diffusion coefficient, D ( $\mathrm{m}^{2}$ $\mathrm{s}^{-1}$ ) following the model of [38]:

$$
\mathrm{F}=(\mathrm{D} \cdot \mathrm{H} / \mathrm{L}) \cdot\left(\mathrm{C}_{\text {Bottom }}-\mathrm{C}_{\mathrm{Top}}\right)
$$

Fick's first law (Eq. 2) expresses the proportionality between the concentration gradient existent through a profile and the diffusive flux resulted across a surface. $H$ is the partition coefficient with a value of 1 in this case since the $\mathrm{CO}_{2}$ is insoluble in the tested samples. $\mathrm{C}_{\mathrm{Bottom}}$ and $\mathrm{C}_{\mathrm{Top}}\left(\mathrm{mol} \mathrm{m} \mathrm{m}^{-3}\right)$ are the concentrations in the bottom and top chambers of the device. $\mathrm{CO}_{2}$ diffusion coefficient is calculated for the different studied samples when the gas passes through its thickness $\mathrm{L}(\mathrm{m})$ from the bottom to the top chamber of the device, considering a mass balance and the concentration conditions described above (bottom chamber at constant concentration and top chamber initially with 0 ppm of $\mathrm{CO}_{2}$ ), using Eq. 3:

$$
\mathrm{C}_{\text {Top }}(\mathrm{t}) / \mathrm{C}^{0}{ }_{\text {Bottom }}=1-\mathrm{e}^{-{ }^{-} \cdot \mathrm{D} \cdot \mathrm{t}}
$$

where $\beta$ is a sample geometry parameter equal to $617.3 \mathrm{~m}^{-2}$ in this particular experiment. A more detailed explanation of the coefficient calculations is described by Zhang et al. [38].

The different hygrometric conditions are automatically established by the injection of water vapour in the laboratory device at different concentrations, depending on the required test conditions. Tested samples were equilibrated with the water vapour after two pre-cycles of the experiment. These pre-cycles were performed before the beginning of the experiment by establishing the experimental conditions (relative humidity and gas concentration) with longer durations $(6-12 \mathrm{~h})$ than the real experimental conditions. Then, the equilibrium between the sample and the gaseous atmosphere of the chambers was ensured for the diffusion experiment. Conditions inside the chambers were recorded with a temperature and relative humidity probe (Rotronic HC2-S3H). A CO 2 probe (GMP222 Vaisala Carbocap) measured $\mathrm{CO}_{2}$ concentration. The temperature inside the chambers remained constant $\left(20^{\circ} \mathrm{C}\right)$ as well as the working pressure (atmospheric pressure). The determination of the gas diffusion coefficient was accomplished under different hygrometric conditions (relative humidities of 20,40,70 and 90\%) with the aim of establishing the effect of the water content in the diffusion coefficient. Although $\mathrm{CO}_{2}$ is a soluble gas, the diffusion of $\mathrm{CO}_{2}$ dissolved in liquid water is negligible compare with the diffusion of $\mathrm{CO}_{2}$ gas. Moreover, $\mathrm{CO}_{2}$ gas consumption in the pore water can be considered scarce because $\mathrm{CO}_{2}$ concentration in the chamber is high and constant. In practice pore water obstructs the direct passage of $\mathrm{CO}_{2}$ and does not act as a $\mathrm{CO}_{2}$ sink. 


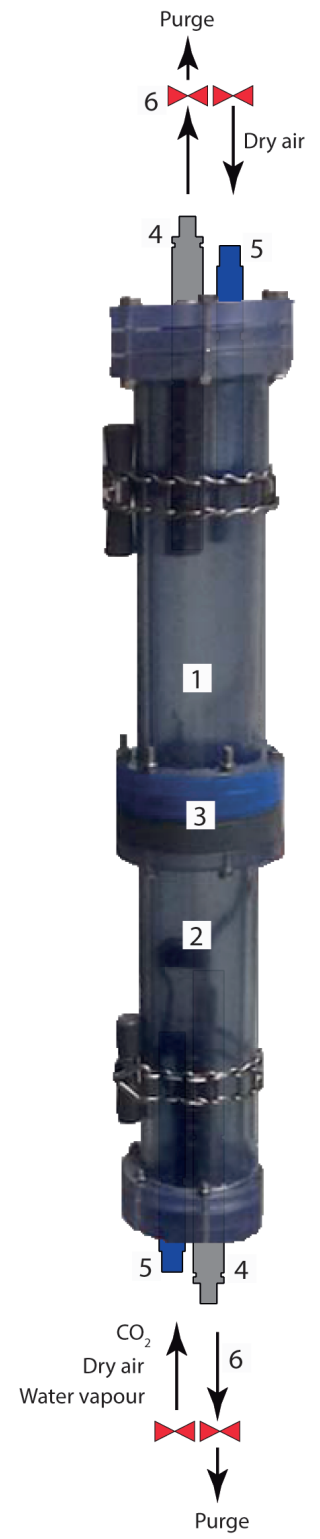

Fig. 3. Gaseous diffusion measurement device. $(1,2)$ Top and bottom chambers. (3) Cell to place the sample. (4) $\mathrm{CO}_{2}$ concentration probe and (5) temperature and relative humidity probe in the top and bottom chamber. (6) Set of valves in the top and bottom chamber.

\section{Results and discussion}

\subsection{Pore structure}

Table 1 shows porosities, permeability coefficients and pore structure parameters of the studied porous stones and Fig. 1 and Fig. 2 display the pore size distribution and water sorption isotherm. The studied porous stones exhibit different petrographic and petrophysical characteristics. They present meso- and macropores according to IUPAC classification [39]. The porous stones have high porosity (15-23\%) and a polymodal pore size distribution (Fig. 1), 
although they show a principal pore population. Pore mean radius, $r_{M}$, quantifies the main pore population and ranges from 0.08 to $34.18 \mu \mathrm{m}$ (Table 1). Pore size distribution also reveals that the porosity below $0.002 \mu \mathrm{m}$ can be considered negligible.

The petrographic characterisation reveals that closed porosity is negligible; therefore, the fraction of large pores is reflected in the total porosity values, which are always slightly higher than the connected porosity. Total and connected porosity are similar in C1, C2, S3 and D4. However, L5 contains large grains or bioclasts, and therefore, has large pore radius that mercury intrusion porosimetry technique cannot measure. As a result, total porosity is higher than connected porosity.

Figure 2 shows the water adsorption curve of the porous materials at different relative humidities. The presence of a bend at a relative humidity of about $75-80 \%$ is the result of the capillarity water condensation for this type of mesoporous materials. Porosity occupied by capillary condensation can be estimated as $\Delta \mathrm{m} / \mathrm{m}_{0, \max } \cdot \rho_{\mathrm{b}} / \rho_{\mathrm{w}}\left(\right.$ or $\left.\theta_{\mathrm{g}} \cdot \rho_{\mathrm{b}} / \rho_{\mathrm{w}}\right)$ using the water isotherm and as $\mathrm{v}_{\mathrm{P}} \cdot\left(\rho_{\mathrm{b}} / \rho_{\mathrm{w}}\right)$ in the nitrogen adsorption characterisation. For example, water-condensate porosity for $\mathrm{C} 1$ is $4.29 \%$, which is the $30 \%$ of its connected porosity. The percentage of the occupied porosity by capillary condensation, $\mathrm{P}_{\mathrm{con}}$, can be calculated as the ratio between watercondensate porosity and connected porosity. This percentage of the occupied porosity varies from 2 to $30 \%$ of the connected porosity (Table 1 ).

The specific surface area, SSA, the pore volume, $\mathrm{v}_{\mathrm{P}}$, and the maximum adsorbed water, $\Delta \mathrm{m} / \mathrm{m}_{0, \text { max }}$, for this kind of building materials are directly related to porosity and inversely related to pore size $[22,40]$. Materials with high porosity and small pore size (e.g.: C1) present a higher SSA, $v_{P}$ and $\Delta \mathrm{m} / \mathrm{m}_{0, \max }$ than materials with small porosity values and large pore radius (e.g.: L1). For instance, a building material with high values of the specific surface area and pore volume implies a high capacity and susceptibility of water condensation and retention into the material. As a consequence, it is prone to deterioration by salt and ice crystallisation, chemical deterioration or the development of microorganisms [21-22, 40].

\subsection{Water and gas permeabilities}

Permeability values of the studied stones range from $10^{-18}$ to $10^{-11} \mathrm{~m}^{2}$ (Table 1 ). Permeability classifications in hydrological studies [41] or hydrocarbon industry (e.g.: [42]) classify them as very low permeable (C1), low permeable (C2 and S3) and permeable stones (D4 and L5). In general, the intrinsic permeability is at the same order of magnitude than water permeability (Fig. 4a). However, $\mathrm{k}_{\mathrm{w}}$ is lower than $\mathrm{k}_{\mathrm{int}}$ for $\mathrm{C} 1$ and $\mathrm{C} 2$ which present few clays and thin pores. This discrepancy might be related to the hygric expansion of the materials. When the clays are present in lithoclasts they can swell and decrease pore space. On the other, the hygric expansion has been attributed to the disjoining pressure and corresponds to the difference in pressure within a water film between two surfaces and the pressure of the bulk phase [43]. Hygric swelling increases with increasing the specific surface area, which increases as pore radius decreases [33] (Table 1). Thus, the hygric expansion in stones may reduce pore size and consequently, the water permeability. The interaction between the fluid and the stone does not 
occur in the gas permeability characterisation, where nitrogen does not interact with rock-forming minerals.

Probably, the simplest model for single-phase permeability was proposed by Kozeny [44] and latter modified by Carman [45]. The Carman-Kozeny equation expresses permeability as a function of pore size, $r$, connected porosity, $\phi_{\mathrm{c}}$, and tortuosity, $\tau$ [46-47], as follows (Eq. 4):

$$
\mathrm{k}=\left(\phi_{\mathrm{c}} \cdot \mathrm{r}^{2}\right) /(8 \cdot \tau)
$$
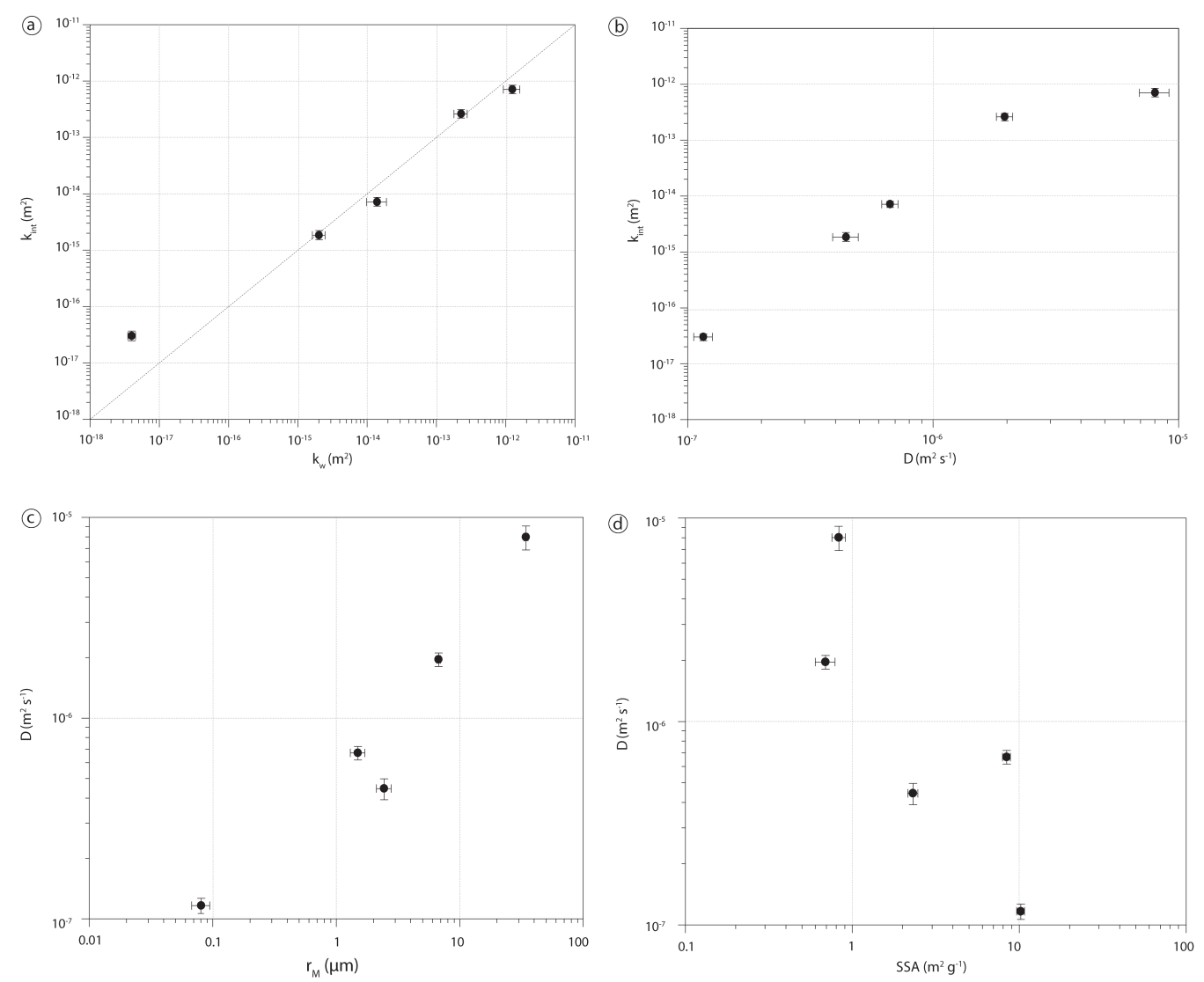

Fig. 4. Correlations between intrinsic gas, $\mathrm{k}_{\mathrm{int}}$, and water permeability, $\mathrm{k}_{\mathrm{w}}, \mathrm{CO}_{2}$ diffusion coefficient, $\mathrm{D}$, pore mean radius, $\mathrm{r}_{\mathrm{M}}$, and specific surface area (SSA) for the studied building stones.

Porous stones with larger pores and higher porosity values present the highest permeability values, although the most determinant pore structure parameter is the pore size. Connected porosity considers not only the accessible pore space volume but also the pore connectedness information. Pore connectedness increases with porosity and is related to the coordination number of the pores. Below $10 \%$ connected porosity, pore connectivity dramatically decreases as a result of the closure and elimination of the throats; meanwhile, in stones where connected porosity is higher than $10 \%$, the reduction of the transport coefficients with porosity is due, almost entirely, to the gradual reduction of the throat dimensions [35, 48-51]. Thus, for example, C2 and S3 present similar pore size distribution and permeability of the biocalcarenite $(\mathrm{C} 2)$ is higher than sandstone (S3) because the latter has a higher porosity value. 
Klinkenberg [37] evaluated the relationship between slip-enhanced and gas permeability at a given head pressure and concluded that the slip parameter, $b$, is inversely related to mean pore size. Jones [52] proposed an empirical relationship between $b$ and permeability, which stated that $b$ is higher for lower permeability materials. Our results present similar values although slightly higher than predicted values by the Jones's empirical equation. Thus, these results show the same slip-enhanced and gas permeability tendency and highlight the role of the pore size in the gas permeability (Table 1).

\subsection{Influence of condensate water on $\mathrm{CO}_{2}$ diffusion coefficients}

As it occurs with the permeability coefficients, porous materials with larger pores and higher porosity values present the highest $\mathrm{CO}_{2}$ diffusion coefficients (Table 1 and Fig. 4c). For example, the limestone (L5) has the highest $\mathrm{CO}_{2}$ diffusion coefficients because it has the largest pore sizes, whereas $\mathrm{C} 1$, with the thinnest pores, consequently exhibits the lowest coefficient. The studied porous stones present high porosity values so that the most determinant pore structure parameter is the pore size. Figure $4 \mathrm{c}$ highlights a clear relationship between the $\mathrm{CO}_{2}$ diffusion coefficient and pore size, describes by the mean radius, $r_{M}$ (Fig. 4c). The influence of pore size distribution on the specific surface area, SSA, is also reflected in diffusion coefficient. SSA increases as pore radius decreases [33]. Figure $4 d$ shows this inverse tendency between specific surface area and $\mathrm{CO}_{2}$ diffusion coefficient.

Table 2 shows the $\mathrm{CO}_{2}$ diffusion coefficients at different air relative humidities. Diffusion coefficients decrease as relative humidity increases because water condensation within the porous system reduces $\mathrm{CO}_{2}$ diffusion. Condensate water at the lowest relative humidity (20\%) can be considered negligible (Figs. 1-2). At this point, the $\mathrm{CO}_{2}$ diffusion coefficient is determined under a porous system free of condensate water and therefore the pore structure in the different stones controls the $\mathrm{CO}_{2}$ diffusion.

Table 2. Calculated $\mathrm{CO}_{2}$ diffusion coefficients, $\mathrm{D}\left(\mathrm{m}^{2} \mathrm{~s}^{-1}\right)$.

\begin{tabular}{|c|c|c|c|c|}
\hline \multirow{2}{*}{ Sample } & \multicolumn{4}{|c|}{ Relative humidity in the chamber device (Dry sample) } \\
\cline { 2 - 5 } & $20 \%$ & $40 \%$ & $70 \%$ & $90 \%$ \\
\hline C1 & $1.16 \cdot 10^{-7} \pm 0.02 \cdot 10^{-7}$ & $9.88 \cdot 10^{-8} \pm 0.22 \cdot 10^{-8}$ & $9.00 \cdot 10^{-8} \pm 0.33 \cdot 10^{-8}$ & $5.96 \cdot 10^{-8} \pm 0.48 \cdot 10^{-8}$ \\
\hline C2 & $6.68 \cdot 10^{-7} \pm 0.11 \cdot 10^{-7}$ & $6.64 \cdot 10^{-7} \pm 0.13 \cdot 10^{-7}$ & $6.15 \cdot 10^{-7} \pm 0.23 \cdot 10^{-7}$ & $5.78 \cdot 10^{-7} \pm 0.52 \cdot 10^{-7}$ \\
\hline S3 & $4.43 \cdot 10^{-7} \pm 0.13 \cdot 10^{-7}$ & $4.37 \cdot 10^{-7} \pm 0.13 \cdot 10^{-7}$ & $4.18 \cdot 10^{-7} \pm 0.19 \cdot 10^{-7}$ & $3.64 \cdot 10^{-7} \pm 0.45 \cdot 10^{-7}$ \\
\hline D4 & $1.96 \cdot 10^{-6} \pm 0.09 \cdot 10^{-6}$ & $1.66 \cdot 10^{-6} \pm 0.12 \cdot 10^{-6}$ & $1.55 \cdot 10^{-6} \pm 0.08 \cdot 10^{-6}$ & $1.12 \cdot 10^{-6} \pm 0.21 \cdot 10^{-6}$ \\
\hline L5 & $8.02 \cdot 10^{-6} \pm 0.25 \cdot 10^{-6}$ & $7.98 \cdot 10^{-6} \pm 0.42 \cdot 10^{-6}$ & $7.89 \cdot 10^{-6} \pm 0.19 \cdot 10^{-6}$ & $7.70 \cdot 10^{-6} \pm 0.92 \cdot 10^{-6}$ \\
\hline
\end{tabular}

The gas diffusion coefficient is affected by stone air-filled porosity, $\varepsilon$, which can be defined as the difference between the volumetric water content and connected porosity. In the literature, several types of expressions have been suggested to represent the relationship between the gas 
diffusion coefficient and the material air-filled porosity. Gas diffusion in porous materials is commonly described using the relative gas diffusion coefficient, $\mathrm{D} / \mathrm{D}_{0}$, which is therefore the ratio of the gas diffusion coefficient in the material to that in free air. Different linear and curvilinear empirical equations describe the relationship between $\mathrm{D} / \mathrm{D}_{0}$ and $\varepsilon$ in the literature [53-61]. For instance, Penman [59] suggested the following linear relationship between the relative diffusion coefficient and air-filled porosity (Eq. 5):

$$
\mathrm{D} / \mathrm{D}_{0}=0.66 \cdot \varepsilon
$$

where 0.66 represents the tortuous length of the pores in the soil. Likewise, we consider a linear equation between relative gas-diffusion coefficient and air-filled porosity (Eq. 6):

$$
\mathrm{D} / \mathrm{D}_{0}=\varepsilon / \tau
$$

where $\mathrm{D}_{0}$ is gas-diffusion coefficient in free air $\left(1.39 \cdot 10^{-5} \mathrm{~m}^{2} \mathrm{~s}^{-1}\right.$ at a temperature of $273.2 \mathrm{~K}$ and an absolute pressure of $100 \mathrm{kPa} ;[55]), \varepsilon$ is the air-filled porosity $\left(\mathrm{cm}^{3} \mathrm{~cm}^{-3}\right)$ and $\tau$ is a factor representing pore tortuosity. The air-filled porosity, $\varepsilon$, can be calculated by subtracting volumetric water content, $\theta_{\mathrm{v}}$, from connected porosity, $\phi_{\mathrm{c}}$, i.e., $\varepsilon=\phi_{\mathrm{c}}-\theta_{\mathrm{v}}$.

Eq. (6) can be expressed as (Eq. 7):

$$
\mathrm{D} / \mathrm{D}_{0}=\mathrm{A} \cdot \varepsilon+\mathrm{B}
$$

where $\mathrm{A}$ and $\mathrm{B}$ are the coefficients of the linear regression.

The air-filled porosity is calculated for the mass of water adsorbed per unit of dried sample $\Delta \mathrm{m} / \mathrm{m}_{0}$ or gravimetric water content, $\theta_{\mathrm{g}}$ (Fig. 2). Thus, the volumetric water content, $\theta_{\mathrm{v}}$, is $\theta_{\mathrm{v}}=$ $\theta_{\mathrm{g}} \cdot \rho_{\mathrm{b}} / \rho_{\mathrm{w}}$, where $\rho_{\mathrm{b}}$ and $\rho_{\mathrm{w}}$ are respectively stone bulk and water density. For the studied stones, A coefficient (Eq. 7) increases as pore size increases being 0.16, 0.47, 1.19, 19.91 and 20.41 respectively for C1, C2, S3, D4 and D5. These samples present similar connected porosity values, always higher than $10 \%$ (i.e. well-established pore connectivity). Thus, $\mathrm{C} 1$ and $\mathrm{C} 2$ present the lowest values of pore radius and A-coefficient whereas D4 and L5, with the higher values of pore size, relate to the higher values of A-coefficient. According to Eqs. (5) and (6), the coefficient A is inversely related to tortuosity factor, $\tau$. Connected porosity quantifies the reduction in the crosssectional area available for gaseous transport, while tortuosity characterises the convoluted nature of the porous pathways followed by diffusing species [62]. Tortuosity factor, $\tau$, represents the ratio of the length of the real path in the network air-filled pores divided by a straight-line value. This parameter considers the complexity of the interconnections, the variability of the pore radius and the roughness of pore wall. In particular, pore size becomes crucial in path length of gas movement. The ratio between the real path and straight-line value $(\tau)$ is higher in porous materials with small pores.

Figure 5 shows the variation of relative gas diffusion coefficient at different relative humidities. Water pore condensation reduces both connected porosity and pore size and therefore, the $\mathrm{CO}_{2}$ diffusion coefficient. This variation takes place in all the studied porous building stones although it is especially important in stones with small pores. For instance, the $\mathrm{CO}_{2}$ gas diffusion coefficient of $\mathrm{C} 1$ decreases by $50 \%$ when relative humidity varied from $20 \%$ to $90 \%$, whereas the 
diffusion coefficient reduction in the limestone (L5) is by $4 \%$. The percentage of the occupied porosity varies from $30 \%$ in $\mathrm{C} 1$ to $2 \%$ in L5 (Table 1 ).

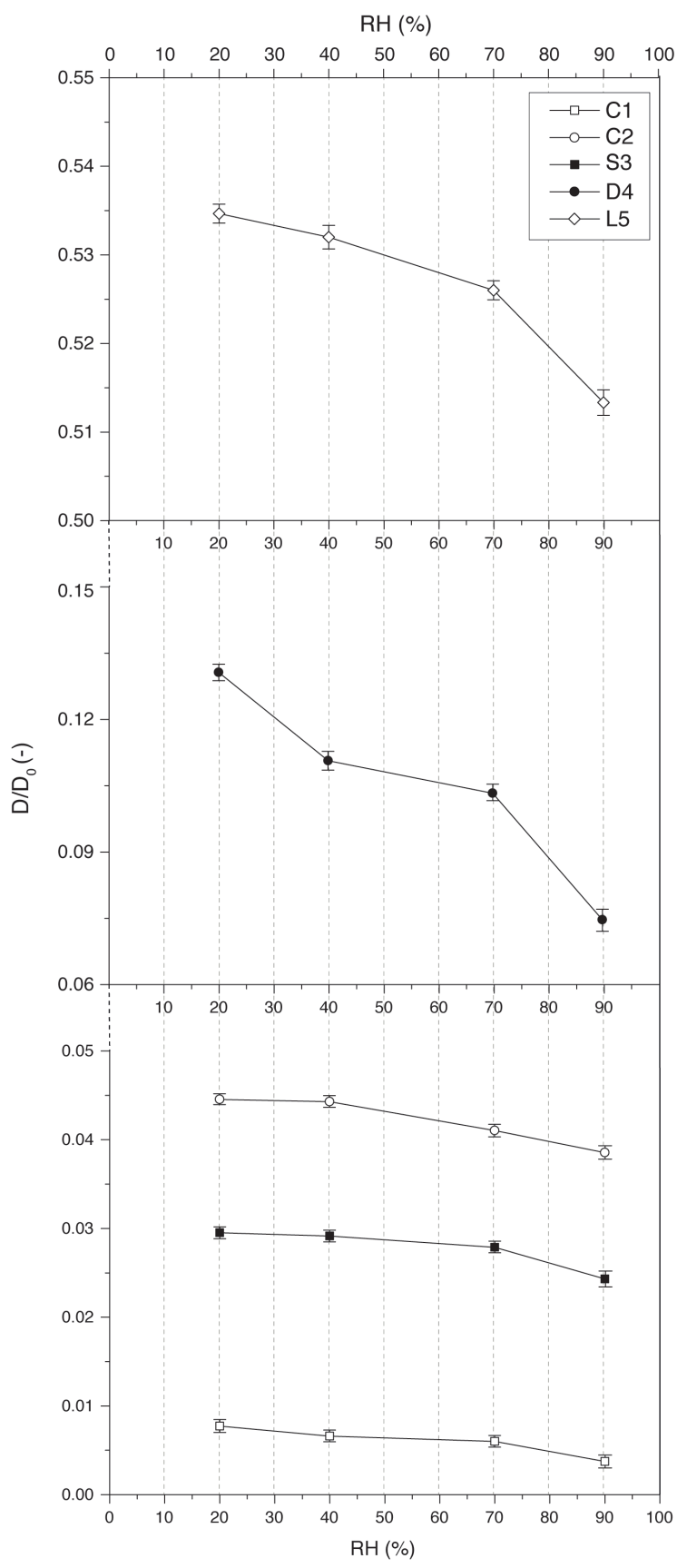

Fig. 5. D/D $\left(\mathrm{D}_{0}\right)$ for the different samples $(\mathrm{C} 1, \mathrm{C} 2, \mathrm{~S} 3, \mathrm{D} 4$ and $\mathrm{L} 5)$ over a range of relative humidity $(20 \%$ to $90 \%)$.

At low relative humidities (first stages of the condensation process), vapour water is adsorbed on pore surface of the stone. With rising air humidity, the number of layers of water molecules on the pore surface increases until capillary condensation occurs for pore radius around $0.1 \mu \mathrm{m}$. Porous stones show this behaviour once the relative humidity reaches $75-80 \%$, as the vapour adsorption curve displays (Fig. 2). As a consequence, when RH exceeds $75 \%$, the content 
of condensate water in pores rises and obstructs the direct passage of vapour. This reduces the available porosity and pore size and, therefore, gas diffusion through the stone, which becomes less permeable to gases as RH approaches $100 \%$. Water condensation in porous building materials is a dynamic process involving the flow of water vapour between the air and a solid surface. The flow can be significant and varies with time. The process alternates water condensation and evaporation, depending on the direction of the vapour gradient between the air and the surface. Effective condensation occurs when vapour pressure in the air is higher than on the stone surface and it is more active due to the presence of thin pores and dissolved salts [11].

Table 1 and Fig. 4d indicate that porous stones with high specific surface area, SSA, present less gas diffusion coefficients due to inverse relationship between SSA and pore size. In addition, high SSA values also indicate a high capacity and susceptibility to water condensation and retention within porous materials [21,33]. Consequently, porous materials with high SSA values will present lower values of gas diffusion coefficients and a sharp variation of diffusion coefficients caused by the water condensation.

Practical interest has the similarity between the pore volume, $\mathrm{v}_{\mathrm{P}}$, and maximum adsorbed water, $\Delta \mathrm{m} / \mathrm{m}_{0, \max }$, in terms of the maximum value of water-condensate porosity. This porosity accounts the porosity reduction to gas diffusion. Water-condensate porosity needs several weeks of testing whereas the obtained in the nitrogen adsorption characterisation requires a few hours of analysis.

\subsection{Relationship between gas permeability and diffusion}

Permeability and gas diffusion coefficients show similar trends (Tables 1 and 2, Fig. 4b). Thus, porous stones with larger pores and higher porosity values present the highest $\mathrm{CO}_{2}$ diffusion and permeability coefficients.

Different expressions, which relate gas permeability and gas diffusion, can be found in the literature, mostly following a power regression model $\left(\mathrm{k}=\mathrm{A} \cdot \mathrm{D}^{\mathrm{n}}\right)$. In this model, constants $\mathrm{A}$ and $\mathrm{n}$ depend on the type of porous material, the humidity and the gas used in the test [30]. For the studied porous materials, the correlation between the intrinsic permeability, $\mathrm{k}_{\text {int }}$, and $\mathrm{CO}_{2}$ diffusion coefficient determined for dried samples, D, is (Eq. 8):

$$
\mathrm{k}_{\text {int }}\left(\mathrm{m}^{2}\right)=7.60 \cdot \mathrm{D}\left(\mathrm{m}^{2} \mathrm{~s}^{-1}\right)^{2.46}
$$

where the squared correlation coefficient of the regression is 0.94 (Fig. 4b). This correlation calculated in other studies performed in soils and cementitious materials with different gases $\left(\mathrm{CO}_{2}\right.$, ${ }^{222} \mathrm{Rn}, \mathrm{O}_{2}$ ) confirmed that $\mathrm{n}$ ranges from 1.3 to 2.5 [30]. The use of gas permeability would simplify the characterisation of porous materials as a gas barrier [10]. However, the estimation of the diffusion coefficient directly from permeability coefficient is not totally accurate due to the constants (A and $\mathrm{n}$ ) dependency on the type of porous material, humidity and gas. Thus, the suggested expression (Eq. 8) would be useful only in case of stones with similar characteristics than the studied here. 


\section{Conclusions}

In this paper, we characterise the $\mathrm{CO}_{2}$ gas diffusion for a wide range of building porous stones and we quantify its variation by water condensation. Results show that the proposed lab methodology properly determines gas diffusion coefficients under different hygrometric conditions.

The studied porous stones exhibit different petrographic and petrophysical properties. The porous stones have a complex porous media with high porosity (15-23\%) and a polymodal pore size distribution. Connected porosities of the studied stones are higher than $10 \%$ and they have well-established pore connectivity.

Results reveal that water pore condensation reduces both connected porosity and pore size and therefore, the $\mathrm{CO}_{2}$ diffusion coefficient. This variation takes place in all the studied porous building stones although it is especially important in stones with small pores. Thus, the $\mathrm{CO}_{2}$ gas diffusion coefficient of $\mathrm{C} 1$ decreases from $1.16 \cdot 10^{-7}$ to $5.96 \cdot 10^{-8} \mathrm{~m}^{2} \mathrm{~s}^{-1}$ when relative humidity varies from $20 \%$ to $90 \%$, whereas the diffusion coefficient reduction in the L5 is by $4 \%$.

For the studied samples, gas and water permeability coefficients present comparable values, which range from $10^{-18}$ to $10^{-11} \mathrm{~m}^{2}$. Permeability and gas diffusion coefficients present similar trends. Thus, porous stones with larger pores (D4 and L5) and higher porosity values present the highest $\mathrm{CO}_{2}$ diffusion, water and gas permeability coefficients. The most determinant pore structure parameter in the transport coefficients is the pore size because it greatly affects both the tortuosity factor of the $\mathrm{CO}_{2}$ gaseous diffusion and the slip parameter of the Klinkenberg's model for gas permeability coefficient.

According, the relationship between gas permeability and gas diffusion fits to power regression model, which can be used to estimate the gas diffusion coefficient from permeability. Our results conclude the power expression would be useful only in case of stones with similar characteristics than the studied in the present paper.

These findings and the proposed methodologies raise important implications for other research fields, including indoor air quality, the characterisation of ${ }^{222} \mathrm{Rn}$ diffusion coefficients in soils and other building materials, preventive conservation of cultural heritage in indoor spaces, control and studies of subterranean terrestrial ecosystems as reservoirs and/or temporary sources of tracer gases.

\section{Acknowledgements}

The authors would like to acknowledge Prof. R.W. Zimmerman for his help during gas permeability experiments and Prof. D. Cazorla-Amorós for his interesting suggestions of pore structure and water condensation. 


\section{Compliance with Ethical Standards:}

This research was funded by the Spanish Ministry of Economy and Competitiveness project CGL2011-25162.

Conflict of Interest: The authors declare that they have no conflict of interest.

\section{References}

[1] Awbi HB (2017) Ventilation for Good Indoor Air Quality and Energy Efficiency. Energy Proc. 112:277-286.

[2] Gall ET, Sonat C, Nazaroff WW, Unluer C (2016) Investigating $\mathrm{CO}_{2}$ removal by Caand Mg-based sorbents with application to indoor air treatment. Buid. Environ. 110:161-172.

[3] Peng S, Hu QH, Hamamoto S (2012) Diffusivity of rocks: Gas diffusion measurements and correlation to porosity and pore size distribution. Water Resour. Res. 48(2): W02507.

[4] Kumar A, Chauhan RP, Joshi M, Sahoo BK (2014) Modeling of indoor radon concentration from radon exhalation rates of building materials and validation through measurements, J. Environ.1 Radioact. 127:50-55.

[5] 2013/59/Euratom: Council Directive 2013/59/Euratom of 5 December 2013 laying down basic safety standards for protection against the dangers arising from exposure to ionising radiation, and repealing Directives 89/618/Euratom, 90/641/Euratom, 96/29/Euratom, 97/43/Euratom and 2003/122/Euratom.

[6] Saad AF, Al-Awami HH, Hussein NA (2014) Radon exhalation from building materials used in Libya, Radiat. Phys. Chem. 101:15-19.

[7] Nazaroff WW, Nero AV (1988) Radon and its decay products in indoor air. John Wiley and Sons Inc., NY.

[8] UNSCEAR, 2000: United Nation Scientific Committee on the Effects of Atomic Radiation: sources, effects and risks of ionizing radiation. New York, United Nations: Report to the General Assembly.

[9] Pacheco-Torgal F (2012) Indoor radon: An overview on a perennial problem. Build. Environ. 58:270-277.

[10] Linares-Alemparte MP (2015) Caracterización del hormigón en relación a la difusión de gases y su correlación con el radón [in Spanish] (PhD Thesis), UPM..

[11] Fernandez-Cortes A, Benavente D, Cuezva S, Cañaveras JC, Alvarez-Gallego M, Garcia-Anton E, Soler V, Sanchez-Moral S (2013). Effect of water vapour condensation on the radon content in subsurface air in a hypogeal inactive-volcanic environment in Galdar cave, Spain. Atmos. Environ. 75(0):15-23.

[12] Beck K, Al-Mukhtar M, Rozenbaum O, Rautureau M (2003) Characterization, water transfer properties and deterioration in tuffeau: building material in the Loire valley - France. Build. Environ. 38(9-10):1151-1162.

[13] Jooss M, Reinhardt HW (2002) Permeability and diffusivity of concrete as function of temperature. Cem. Concr. Res. 32(9):1497-1504. 
[14] Jung SH, Lee MK, Kim JS (2005) Experimental study on $\mathrm{CO}_{2}$ diffusivity in cementitious materials. Corros. Sci. Techn. 4(2):69-74.

[15] Baroghel-Bouny V (2007) Water vapour sorption experiments on hardened cementitious materials. Part II: Essential tool for assessment of transport properties and for durability prediction. Cem. Concr. Res. 37(3):438-454.

[16] Davidson EA, Belk E, Boone RD (1998) Soil water content and temperature as independent or confounded factors controlling soil respiration in a temperate mixed hardwood forest. Global Change Biol. 4(2):217-227.

[17] Epron D, Farque L, Lucot E, Badot PM (1999) Soil $\mathrm{CO}_{2}$ efflux in a beech forest: dependence on soil temperature and soil water content. Ann. For. Sci. 56(3):221-226.

[18] Pla C, Cuezva S, Martinez-Martinez J, Fernandez-Cortes A, Garcia-Anton A, Fusi N, Crosta GB, Cuevas-Gonzalez J, Cañaveras JC, Sanchez-Moral S, Benavente D (2017) Role of soil pore structure in water infiltration and $\mathrm{CO}_{2}$ exchange between the atmosphere and underground air in the vadose zone: A combined laboratory and field approach. Catena 149:402-416.

[19] Sanci R, Panarello HO, Ostera HA (2009) Assessment of soil moisture influence on $\mathrm{CO}_{2}$ flux: a laboratory experiment. Environ. Geol. 58(3):491-497.

[20] Varas-Muriel MJ, Fort R, Martínez-Garrido MI, Zornoza-Indart A, López-Arce P (2014) Fluctuations in the indoor environment in Spanish rural churches and their effects on heritage conservation: Hygro-thermal and $\mathrm{CO}_{2}$ conditions monitoring. Build. Environ. 82:97-109.

[21] Sanchez-Moral S, Luque L, Cuezva S, Soler V, Benavente D, Laiz L, Gonzalez JM, Saiz-Jimenez C (2005) Deterioration of building materials in Roman catacombs: The influence of visitors. Sci. Total Environ. 349(1-3):260-276.

[22] Benavente D, Sanchez-Moral S, Fernandez-Cortes A, Cañaveras JC, Elez J, SaizJimenez C (2011) Salt damage and microclimate in the Postumius Tomb, Roman Necropolis of Carmona, Spain. Environ. Earth Sci. 63(7):1529-1543.

[23] Cañaveras JC, Fernandez-Cortes A, Elez J, Cuezva S, Jurado V, MIller AZ, RogerioCandelera MA, Benavente D, Hernández-Mariné M, Saiz-Jimenez C, Sanchez-Moral S (2015) The deterioration of Circular Mausoleum, Roman Necropolis of Carmona, Spain. Sci. Total Environ. 518-519:65-77.

[24] Tang JW, Baldocchi DD, Qi Y, Xu LK (2003) Assessing soil $\mathrm{CO}_{2}$ efflux using continuous measurements of $\mathrm{CO}_{2}$ profiles in soils with small solid-state sensors. Agric. Forest Meteorol. 118(3-4):207-220.

[25] Turcu VE, Jones SB, Or D (2005) Continuous soil carbon dioxide and oxygen measurements and estimation of gradient-based gaseous flux. Vadose Zone J. 4(4):1161-1169.

[26] Namoulniara K, Turcry P, Aït-Mokhtar A (2016) Measurement of $\mathrm{CO}_{2}$ effective diffusion coefficient of cementitious materials. Eur. J. Environ. Civ. Eng. 20(10):1183-1196.

[27] Gao Z, Hu Q, Liang H (2013) Gas diffusivity in porous media: determination by mercury intrusion porosimetry and correlation to porosity and permeability. J. Porous Media 16(7).

[28] Rahmati M, Neyshaboury MR (2016) Soil Air Permeability Modeling and Its Use for Predicting Unsaturated Soil Hydraulic Conductivity. Soil Sci. Soc. Am. J. 80(6):1507-1513. 
[29] Kameche ZA, Ghomari F, Choinska M, Khelidj A (2014) Assessment of liquid water and gas permeabilities of partially saturated ordinary concrete. Const. Build. Mater. 65(0):551565 .

[30] Klink T, Gaber K, Schlattner E, Setzer MJ (1999) Characterisation of the gas transport properties of porous materials by determining the radon diffusion coefficient. Mater. Struct. 32(10):749-754.

[31] Benavente D (2003) Modelización y estimación de la durabilidad de materiales pétreos porosos frente a la cristalización de sales [in Spanish] ( $\mathrm{PhD}$ Thesis). University of Alicante (http://www.cervantesvirtual.com/FichaObra.html?Ref=12011, Accessed: 29/03/2017).

[32] Benavente D, García del Cura MA, Fort R, Ordóñez S (2004) Durability estimation of porous building stones from pore structure and strength. Eng. Geol. 74(1-2):113-127.

[33] Benavente D, Cultrone G, Gómez-Heras M (2008) The combined influence of mineralogical, hygric and thermal properties on the durability of porous building stones. Eur. J. Mineral. 20(4):673-685.

[34] UNE-EN 1936:2007: Natural stone test methods - Determination of real density and apparent density, and of total and open porosity

[35] Benavente D, Cueto N, Martínez-Martínez J, García del Cura MA, Cañaveras JC (2007) The influence of petrophysical properties on the salt weathering of porous building rocks. Environ. Geol. 52(2):215-224.

[36] Galvan S, Pla C, Cueto N, Martínez-Martínez J, García del Cura MA, Benavente D (2014) A comparison of experimental methods for measuring water permeability of porous building rocks. Materiales de Construcción 64(315):028.

[37] Klinkenberg LJ (1941) The Permeability of Porous Media to Liquids and Gases. SOCAR Proceedings 2(2):200-213.

[38] Zhang ZH, Ouriadov AV, Willson C, Balcom BJ (2005) Membrane gas diffusion measurements with MRI. J. Magn. Reson. 176(2):215-222.

[39] Rouquerol J, Avnir D, Fairbridge C, Everett D, Haynes J, Pernicone N, Ramsay J, Sing K, Unger K (1994) Recommendations for the characterization of porous solids (Technical Report). Pure Appl. Chem. 66(8):1739-1758.

[40] Benavente D (2001) Why pore size is important in the deterioration of porous stones used in the built heritage. Macla 15:41-42.

[41] Hölting B (1989) Hydrogeologie. Auflage, Stuttgart: Ferdinand Enke Verlag.

[42] Lianbo Z, Xiang-Yang L (2009) Fractures in sandstone reservoirs with ultra-low permeability: A case study of the Upper Triassic Yanchang Formation in the Ordos Basin, China. AAPG Bulletin 93(4):461-477.

[43] Steiger M, Charola AE (2011) Weathering and deterioration. In: Siegesmund S, Snethlage R (Eds.), Stone in Architecture, Springer-Verlag, Berlin Heidelberg. pp. 227-316.

[44] Kozeny J (1927) Über kapillare Leitung des Wassers im Boden. Akad. Wiss. Wien. 136:271-306.

[45] Carman PC (1997) Fluid flow through granular beds. Chem. Eng. Res. Des. 75:S32S48. 
[46] Bear J (2013) Dynamics of fluids in porous media. Courier Corporation.

[47] Dullien FA (2012) Porous media: fluid transport and pore structure. Academic press.

[48] Wong PZ, Koplik J, Tomanic JP (1984) Conductivity and permeability of rocks. Phys. Rev. B: Condens. Matter. 30(11):6606-6614.

[49] Bourbie T, Zinszner B (1985) Hydraulic and acoustic properties as a function of porosity in Fontainebleau Sandstone. J. Geophys. Res. B: Solid Earth 90(B13):11524-11532.

[50] Doyen PM (1988) Permeability, conductivity, and pore geometry of sandstone. J. Geophys. Res. B: Solid Earth 93(B7):7729-7740.

[51] Benavente D, Pla C, Cueto N, Galvañ S, Martínez-Martínez J, García del Cura MA, Ordóñez S (2015) Predicting water permeability in sedimentary rocks from capillary imbibition and pore structure. Eng. Geol. 195:301-311.

[52] Jones SC (1972). A rapid accurate unsteady-state Klinkenberg permeameter. Soc. Pet. Eng. J. 12(5):383-397.

[53] Buckingham E (1904) Contributions to our knowledge of the aeration of soils. Bulletin 25 - USDA Bureau of Soils. U.S. Government Printing Office, Washington, DC. 52 pp.

[54] Currie JA (1960) Gaseous diffusion in porous media Part 1. A non-steady state method. Br. J. Appl. Phys. 11(8):314.

[55] Jabro JD, Sainju UM, Stevens WB, Evans RG (2012) Estimation of $\mathrm{CO}_{2}$ diffusion coefficient at 0-10 cm depth in undisturbed and tilled soils. Arch. Agron. Soil Sci. 58(1):1-9.

[56] Marshall T (1959) The diffusion of gases through porous media. Eur. J. Soil Sci. 10(1):79-82.

[57] Millington R, Quirk JP (1960) Permeability of porous solids. Trans. Faraday Soc. 57(8):1200-1207.

[58] Moldrup P, Kruse CW, Rolston DE, Yamaguchi T (1996) Modeling diffusion and reaction in soils. 3. Predicting gas diffusivity from the Campbell soil-water retention model. Soil Sci. 161(6):366-375.

[59] Penman HL (1940) Gas and vapour movements in the soil II. The diffusion of carbon dioxide through porous solids. J. Agric. Sci. 30:570-581.

[60] Ridgwell AJ, Marshall SJ, Gregson K (1999) Consumption of atmospheric methane by soils: A process-based model. Global Biogeochem. Cycles 13(1):59-70.

[61] Troeh FR, Jabro JD, Kirkham D (1982) Gaseous-diffusion equations for porous materials. Geoderma 27(3):239-253.

[62] Jabro JD (2009) Water Vapor Diffusion Through Soil as Affected by Temperature and Aggregate Size. Transp. Porous Media 77(3):417-428. 